\title{
PROEJA - DESAFIOS DO ENSINAR EM MATEMÁTICA NO ENSINO REMOTO
}

\section{PROEJA - CHALLENGES OF TEACHING MATHEMATICS IN REMOTE TEACHING}

\author{
Cristiane da Silva Stamberg ${ }^{1}$
}

\begin{abstract}
RESUMO
$\mathrm{O}$ artigo discute as ferramentas adotadas com uma turma de PROEJA (Programa Nacional de Integração da Educação Profissional com a Educação Básica, Modalidade de Jovens e Adultos), na disciplina de matemática durante as atividades remotas ocasionadas pelo surto do Covid-19. A turma do Curso Técnico em Estética Integrado- $2^{\circ}$ ano é composta por 15 alunas, que na grande maioria são mães, que trabalham durante o dia e que voltaram a estudar após vários anos afastados da escola. O desafio inicial foi organizar estratégias, para que os conceitos da disciplina de matemática, as alunas tivessem condições de acompanhar as aulas e também dar conta de todas as demais atividades de seu dia-a-dia, com efetividade de aprendizagem no curso após vários anos afastados da escola. O curso Técnico em Estética Integrado iniciou as atividades na Instituição em 2015, o curso faz parte do rol de cursos do Catálogo Nacional dos Cursos Técnicos, no Eixo Tecnológico Ambiente e Saúde. O presente texto, trata-se de um relato que apresenta as possibilidades que foram criadas para dar continuidade à aprendizagem das mesmas nesse período de atividades remotas. Dessa maneira, uma das formas encontradas para promover o acompanhamento da disciplina, foi a criação de um grupo de WhatsApp somente para disciplina, para envio de materiais em arquivos PDF, estes que permitem download mais facilmente. Também foi realizado o uso de vídeos, com explicações da docente relacionados aos conceitos enviados. O uso desses materiais através de envio vídeos e arquivos via WhatsApp, como facilitador das dificuldades de acesso e entendimentos da plataforma institucional utilizada pelos estudantes do Instituto Federal Farroupilha. Assim, o relato apresenta as estratégias usadas, relatos dessas alunas em relação ao material utilizado e a eficácia de uma organização simples. Procura também apresentar imagens de alguns dos vídeos feitos para a turma e defender este como recurso tecnológico como importante no processo educacional. Estratégias de ensino, para a disciplina de matemática entre jovens e adultos são desafios constante, assim como para outras áreas do conhecimento, pois os mesmos deixaram o sistema escolar por muito tempo e agora estão voltando. O professor precisa sempre estar adequando às metodologias de ensino, procurando alternativas diferentes para desenvolver os conteúdos, de forma que o aluno possa se sentir interessado e procurando ampliar o aprendizado e principalmente tornar esse significativo. Por fim, este texto também apresenta algumas angústias e as inquietações frente o desafio do ensino remoto, mostrando a importância de diferentes interações e orientações, necessárias nesse momento em que vivemos para permanência e êxito de nossos alunos. Enfim, muitas foram às aprendizagens durante o ensino remoto e esse texto nos faz repensar nossa prática, não só para o
\end{abstract}

\footnotetext{
${ }^{1}$ Doutorado em Educação nas Ciências (UNIJUÍ). Professora de matemática do Ensino Básico, Técnico e Tecnológico do Instituto Federal Farroupilha-Campus Santo Ângelo (Iffar), Santo Ângelo, RS, Brasil. Rua Vinte e dois de março, 502, Centro, Santo Ângelo, RS, Brasil, CEP:98803-040. Email: cristiane.stamberg@iffarroupilha.edu.br.
} 
período de pandemia, mas para além desse, desenvolver metodologias que asseguram uma efetividade de ensino e aprendizagem, atendendo a necessidade dos alunos reinventando as práticas fora dos espaços presenciais.

Palavras-chave: Aprendizagem, Ensino remoto; Matemática; Metodologias; PROEJA.

\begin{abstract}
The article discusses the tools adopted with a class of PROEJA (National Program for the Integration of Professional Education with Basic Education, Youth and Adult Modality), in the discipline of mathematics during remote activities caused by the Coronavirus outbreak (Covid19). The class of the Technical Course in Integrated Aesthetics - 2nd year is composed of 15 students, who are mostly mothers, who work during the day and who returned to study after several years away from school. The initial challenge was to organize strategies, so that the concepts of the mathematics discipline, the students would be able to follow the classes and also take care of all the other activities of their day-to-day, with learning effectiveness in the course after several years. away from school. The Technical course in Integrated Aesthetics started its activities at the Institution in 2015, the course is part of the list of courses in the National Catalog of Technical Courses, in the Environment and Health Technological Axis. This text is a report that presents the possibilities that were created to continue their learning in this period of remote activities. Thus, one of the ways found to promote the monitoring of the discipline, was the creation of a group of WhatsApp only for discipline, to send materials in PDF files, which allow download more easily. The use of videos was also carried out, with explanations from the teacher related to the concepts sent. The use of these materials by sending videos and files via WhatsApp, as a facilitator of the difficulties of access and understanding of the institutional platform used by the students of the Federal Farroupilha Institute. Thus, the report presents the strategies used, reports by these students in relation to the material used and the effectiveness of a simple organization. It also seeks to present images of some of the videos made for the class and defend this as a technological resource as important in the educational process. Teaching strategies for the discipline of mathematics between young people and adults are constant challenges, as well as for other areas of knowledge, as they left the school system for a long time and are now coming back. The teacher must always be adapting to the teaching methodologies, looking for different alternatives to develop the content, so that the student can feel interested and trying to expand the learning and especially to make it meaningful. Finally, this text also presents some anxieties and concerns regarding the challenge of remote education, showing the importance of different interactions and orientations, necessary in this moment in which we live for the permanence and success of our students. Anyway, many went to learning during remote education and this text makes us rethink our practice, not only for the pandemic period, but beyond that, develop methodologies that ensure effective teaching and learning, meeting the needs of students by reinventing their needs. practices outside the face-to-face spaces.
\end{abstract}

Keywords: Learning, Remote teaching; Math; Methodologies; PROEJA. 


\section{Introdução}

Com o surto do Covid-19, as instituições de ensino tiveram que pensar e reinventar formas de ensinar através das atividades remotas e, consequentemente, os professores tiveram que pensar e organizar formas para realização das atividades escolares não presenciais. Um dos grandes desafios são as turmas que agregam os alunos dos cursos PROEJA (Programa Nacional de Integração da Educação Profissional com a Educação Básica, Modalidade de Jovens e Adultos), em adequar-se a esse novo modelo de atividade remota emergencial, pois estes possuem especificidades e singularidades diferentes dos demais estudantes, com condições de vida e de trabalho, ou não trabalho nesse momento.

Os cursos na modalidade PROEJA, surgiram a partir do decreto $n^{\circ} 5.478$, de 24 de junho de 2005, que foi instituído no âmbito das instituições federais de educação científica e tecnológica. Em 2006, a promulgação do Decreto $n^{\circ} 5.840$, de 13 de julho de 2006, o PROEJA passa a ter seus contornos atuais, passando a contemplar as etapas Ensino Fundamental e Ensino Médio, em que as instituições que passam a oferecer o programa, contemplam entidades privadas nacionais de serviço social, aprendizagem e formação profissional e instituições dos sistemas de ensino estaduais, municipais e federal, determinando para este último a oferta obrigatória de $10 \%$ das vagas da Educação Básica Profissional ao PROEJA.

O PROEJA surge este contexto:

Originário do Decreto $\mathrm{n}^{\mathrm{o}}$. 5.478, de 24/06/2005, e denominado inicialmente como Programa de Integração da Educação Profissional ao Ensino Médio na Modalidade Educação de Jovens e Adultos, o PROEJA expôs a decisão governamental de atender à demanda de jovens e adultos pela oferta de educação profissional técnica de nível médio, da qual, em geral, são excluídos, bem como, em muitas situações, do próprio ensino médio. (BRASIL, 2007, p. 12).

Esses cursos devem proporcionar uma formação humanística, integral, na qual os conhecimentos partam da prática social e possam contribuir para a transformação de sua realidade. Assim, busca a formação de cidadãos comprometidos com a realidade social, autônomos e empreendedores. Assim, nessa forma de educação profissional, é priorizada a Formação Técnica aliada a Formação Geral. Vale dizer que estas precisam ser trabalhadas de maneira contextualizada, procurando desenvolver metodologias e práticas educativas que relacionem teoria e prática, para um público que há muito tempo não está mais na escola, visto que ficou à margem do sistema escolar. 
O Instituto Federal Farroupilha-Campus Santo Ângelo, possui essa modalidade, que é o Curso Técnico em Estética Integrado, que iniciou as atividades na Instituição desde o ano de 2015. Esse curso faz parte do rol de cursos do Catálogo Nacional dos Cursos Técnicos, no Eixo Tecnológico Ambiente e Saúde.

A oferta desse curso, bem como, toda a oferta de Educação Profissional e Tecnológica no Instituto Federal Farroupilha, se dá em observância à Lei de Diretrizes e Bases da Educação Nacional no 9.394/1996. Esta oferta também ocorre em consonância com as Diretrizes Curriculares Nacionais para a Educação Profissional Técnica de Nível Médio, propostas pela Resolução CNE/ CEB nº 06, de 20 de setembro de 2012 e, em âmbito institucional, com as Diretrizes Institucionais da organização administrativodidático-pedagógica para a Educação Profissional Técnica de Nível Médio no Instituto Federal Farroupilha e demais legislações nacionais vigentes

Como já mencionado, a organização curricular deve priorizar a formação integral, e, também, considerar que a grande maioria do público é formada por adultos e que estes trabalham durante o dia e estudam à noite. Agora nesse momento de pandemia também compartilham de momentos que tornam o ensino ainda mais difícil, como auxiliar os filhos no estudo em casa, desemprego, dificuldade de usar a tecnologia e muitos outros fatores. Trabalhar com PROEJA para muitos educadores é um desafio, pois requer mais do que domínio da disciplina em que é regente, trata-se de levar seus conhecimentos ao nível em que se observam as necessidades e historicidade do público em questão.

Na grande maioria das turmas, encontramos uma miscigenação de pessoas com vastas experiências em diversos trabalhos, que trazem consigo suas vivências de vida. Levando em conta, que esses alunos possuem um histórico de evasão escolar em tempo escolar, por não encontrar motivos para continuar estudando, por achar que os conhecimentos adquiridos em sala de aula não serão de valia para seu futuro, e acreditar que ingressando o quanto antes no trabalho terá mais frutos que investir na educação, faz com que a Educação de Jovens e Adultos encontre dificuldades no caminho para aliar a aprendizagem escolar e as dificuldades diárias, ainda mais nesse momento de pandemia.

Nesse sentido, é preciso reconhecer que existem muitos fatores que limitam a realização das atividades, e uma delas é ausência de estrutura tecnológica nas moradias das estudantes, contando muitas vezes, apenas com o celular e ainda este precisa ser dividido as atividades de estudo dos filhos. 
Por todas essas circunstâncias acima descritas, este texto relata as experiências com uma turma do Curso Técnico em Estética Integrado - $2^{\circ}$ ano, na disciplina de matemática, com 15 alunas, todas mulheres, que na grande maioria são mães, que trabalham durante o dia e que voltaram aos estudos após vários anos afastadas da escola. Para dar continuidade à aprendizagem das mesmas e possibilitar o acompanhamento dos conceitos de aula e entendimento da disciplina nesse período de atividades remotas, foi preciso buscar ferramentas que permitiam chegar ao alcance e condições de vida das mesmas, para efetivamente dispor e dar oportunidades de aprendizagem.

O planejamento das atividades contou com materiais que oferecem não só explicação do conceito matemático e exercícios para serem realizados no caderno. As alunas passaram a receber também pequenos vídeos, com explicação de cada exercício, utilizando um aplicativo que possibilita gravação e edição de vídeo, chamado Glitch Cam Pro. Nos vídeos as alunas visualizavam os conceitos, da mesma forma como eram explicados em sala de aula, fazendo uso de quadro para detalhamento e explicações dos conteúdos.

Dessa maneira, uma das formas encontradas para promover o acompanhamento da disciplina, primeiramente foi criado um grupo de WhatsApp somente para disciplina de matemática. Nesse grupo os materiais eram enviados em arquivos PDF para serem baixados no celular mais facilmente, aliado ao uso de vídeos como uma tecnologia de fins pedagógicos e como instrumento de ensino e aprendizagem, com explicações da docente, sobre cada conceito, tais adaptações por saber que as alunas tinham dificuldades de acesso e entendimentos da plataforma institucional utilizada pela grande maioria dos estudantes do Instituto Federal Farroupilha.

Essas experiências poderiam ser melhores, talvez com outros recursos, mas para o momento, contextualiza a importância do uso de ferramentas, como o uso de vídeos, na prática escolar, possibilitando a continuidade e êxito das alunas. Tais estratégias foram usadas de forma mais clara e explicada, aproximando ao modelo de aula presencial, ao mesmo tempo que aproveita das tecnologias disponíveis no apoio ao ensino e aprendizagem. Também na sequência, estão relatos dessas alunas em relação ao material utilizado e a eficácia de uma organização simples, objetivando envolvimento e compreensão do que está sendo ensinado. 


\section{A matemática para ensinar jovens e adultos}

Atualmente há muitas reflexões a respeito das dificuldades de aprendizado em relação à disciplina de matemática em todos os níveis e modalidades de ensino, e na Educação de Jovens e Adultos, essa situação se acentua bastante, principalmente pelo tempo que ficaram fora da escola, então, faz-se necessário, que os conceitos possam contribuir na promoção de uma aprendizagem mais efetiva desta disciplina, de forma que o ensino não se restrinja a uma dimensão somente conteúdista. Os conceitos ensinados precisam ir ao encontro da realidade das estudantes, contribuindo para o melhor entendimento dos conteúdos e possibilitando que estes percebam a matemática como algo útil para o seu dia-dia e para o curso que estão fazendo.

De acordo com os Parâmetros Curriculares Nacionais para o Ensino Médio (BRASIL, 2000), a contextualização é um recurso para tornar a aprendizagem significativa ao associá-la com conhecimentos que já possuem ou com experiências da vida diária.

Assim, a ensinar a matemática, para o PROEJA, precisa-se de uma forma na qual o seu ensino possa torna-se prazeroso e eficaz, e que entendam o que está sendo ensinado. Tal fato demanda uma avaliação constante dos métodos utilizados no cotidiano escolar, sendo primordias que tais métodos, conduzam para um aprendizado que promova efetividade na sua formação humana e técnica.

Torna-se necessário conversar com os alunos e questioná-los em sala sobre os assuntos que venham ao encontro de seus interesses, e quais eles sentem mais dificuldade em compreender no cotidiano. Assim ao planejar as aulas a contextualização a partir de conceitos matemáticos, auxilia no entendimento dos conceitos relacionados a disciplina.

\footnotetext{
Trata-se de apresentá-los em uma ou mais situações em que façam sentido para os alunos, por meio de conexões com questões do cotidiano dos alunos, com problemas ligados a outras áreas do conhecimento, ou ainda por conexões entre os próprios temas matemáticos (algébricos, geométricos, métricos etc.) (BRASIL, 2002, p. 15).
}

O mais importante, é mostrar que a matemática, precisa fazer sentido e que estes faze parte de situações do cotidiano. Os recursos utilizados para ensinar a matemática precisam também ser atrativos, com métodos que possam sanar as dificuldades. Dessa forma, um bom planejamento nessa modalidade é fundamental, que contemple os 
conhecimentos prévios dos alunos, suas bagagens de vida e outros, agregando ao ensino e aprendizagem da matemática.

Também é válido dizer, que muitos dos alunos que retornaram a escola, carregam certo medo pela matemática e trabalhar os conceitos trazendo significado para os mesmos, o aprendizado contribui também em melhorar o meio em que vivem, possibilitando ajudá-los a resgatar e desenvolver o gosto pelo aprender. Na Proposta Curricular para a educação de jovens e adultos, observa-se tal fato,

A maioria dos jovens e adultos que retomam os estudos já tiveram experiências negativas com o saber matemático. Portanto, as concepções que eles têm sobre a matemática assim como sobre seu papel como alunos são fatores cruciais para a aprendizagem na EJA. (BRASIL, 2002, p. 16)

Neste texto, está apresentado alguns dos conceitos que foram estudados no primeiro momento, que são relativos aos conjuntos numéricos (números naturais, inteiros, racionais, irracionais, reais), conceito este que possibilita aplicação em diferentes contextos, identificando os diferentes conjuntos e subconjuntos.

Para que houvesse efetividade nas aulas, primeiramente foi criado um grupo de watts somente para disciplina de matemática. Esse grupo com o intuito de possibilitar as alunas uma interação maior com a professora para dirimir as dúvidas em relação ao conceito ensinado.

Nesse grupo era enviado todo o material em PDF, tal como era também colocado no Sistema Integrado de Gestão de Atividades Acadêmicas (SIGAA), possibilitando que as alunas pudessem baixar de forma mais rápida, ocupando menos dados de internet nos seus aparelhos de celulares.

Como nas aulas presenciais, as alunas gostavam muito das explicações realizadas no quadro, os vídeos para as aulas no ensino remoto, seguiram essa proposta, com o intuito de manter o vínculo e o ensino mais próximo do presencial, como sendo um instrumento enriquecedor, que desenvolve a linguagem, a criatividade, a imaginação e possibilita aos alunos enxergar de forma efetiva as aulas.

A gravação dos vídeos utilizou o aplicativo Glitch Cam Pro. Este permite de forma rápida e intuitiva, também selecionar fotos, colocar títulos, legendas, cores, músicas e demais efeitos. Dessa forma, foram enviados vários vídeos curtos, com explicações no quadro como era feito na aula presencial. Os vídeos eram encaminhados 
a partir de links disponibilizados pelo canal da docente no Youtube, possibilitando assistir em qualquer momento e assim, em que a internet esteja disponível, possibilitando uma organização para seus horários de estudo e demais afazeres de cada um.

Freire (1987, p. 20) entende que uma aprendizagem significativa se dará a partir de um processo que proporcione uma análise crítica da prática social dos homens, contribuindo para que estes repensem a forma de atuar no mundo. E a inserção das novas tecnologias de informação e comunicação na escola, com o uso de vídeos, aponta caminhos para a evolução tecnológica e os novos desafios de ensinar também propiciando que a aprendizagem torne-se significativa.

A aprendizagem significativa através dos vídeos ainda é desafio, mas sua utilização bem aplicada abre possibilidades para compreensão do que é ensinado e uma maior eficiência sobre a explicação dos conceitos. Para isso, é importante pesquisar, aprender a elaborar e buscar progressos nos próprios vídeos, fazendo que os mesmos possam ser dinâmicos e atrativos. Também o conhecimento sofre um processo de contínua elaboração de significados, através desse recurso da tecnologia da informação, que está a serviço dos objetivos de ensino e aprendizagem. (MOREIRA, 2006).

Abaixo a figura 1, referente ao aplicativo de gravação e edição dos vídeos:

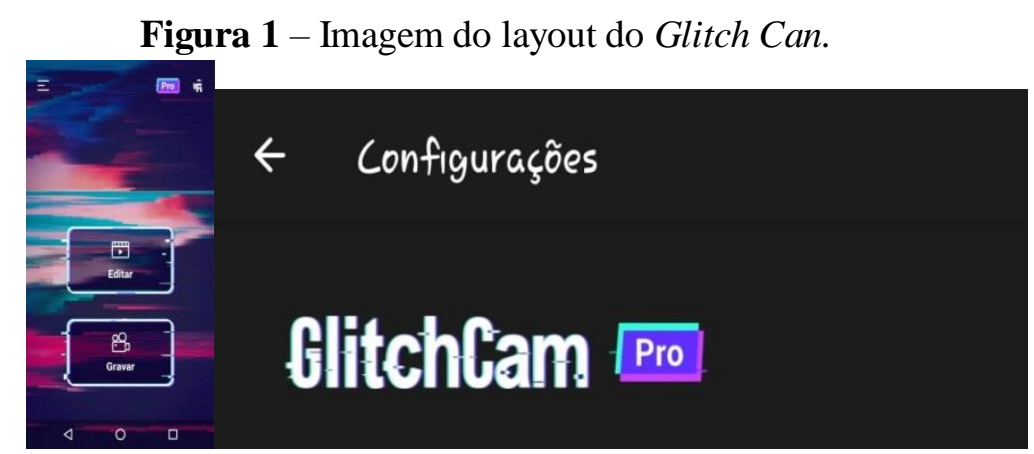

Fonte: Arquivo Pessoal (2020).

Desta forma, considerando as particularidades do público atendido na turma de segundo ano PROEJA e as dificuldades de aprendizado das estudantes na área de matemática, os vídeos objetivaram além da aproximação, uma proposta pedagógica flexível e ao alcance de todas, abaixo as imagens ilustram alguns desses vídeos disponibilizados, conforme figura 2 e 3 : 
Figura 2 - Explicando passo a passo os exercícios.

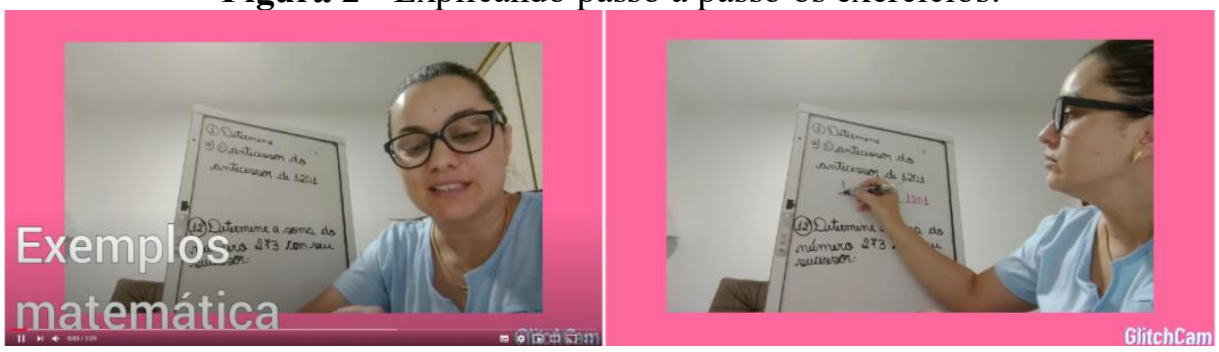

Fonte: Arquivo Pessoal (2020).

A utilização de vídeos tem garantido uma aprendizagem significativa, principalmente porque as alunas enxergam a presença do professor explicando os conceitos da disciplina, oferecendo formas alternativas para que o aluno possa representar e estudar em casa, continuando a adquirir os conhecimentos como eram ensinados anteriormente.

Quando se trata de matemática, o vídeo pode ter papel novo e relevante no ambiente de ensino, pois ele permite a visualização de tudo o que é ensinado, possibilitando detalhes da explicação do conceito e também apresentação atraente.

Figura 3 - Introduzindo a explicação de conjuntos numéricos.

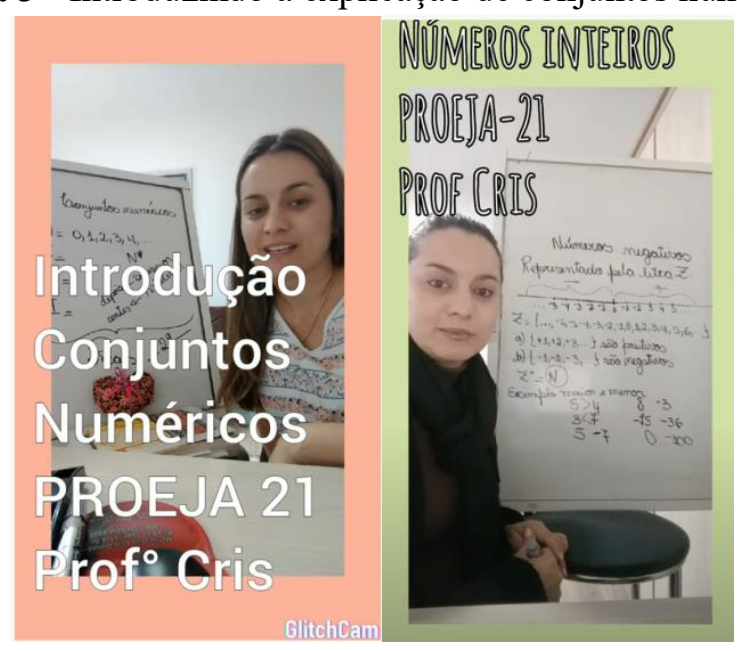

Fonte: Arquivo Pessoal (2020).

O uso dessa ferramenta, como recurso didático, assim como diversos outros, desde que planejado, tem grande potencial e torna-se aliado de alunos e professores no processo de ensino e aprendizagem. Segundo Valente (2005), tanto o aluno como o professor é desafiado a entender que essas novas metodologias de ensino e aprendizagem implicam em novas estratégias, ainda mais nesse momento que todos estão passando com o Covid- 
19. Os vídeos têm por objetivo sanar as dificuldades das alunas e servir de instrumento para elaboração de atividades didáticas que são enviadas juntamente com a explicação dos conceitos. Para Moran (1993), o video é: sensorial, visual, linguagem falada, linguagem musical e escrita.

Toda semana o material enviado ia acompanhado desses vídeos explicativos, que remetiam a mesma maneira das atividades realizadas na forma presencial. Oliveira e Pinheiro (2009), afirmam que o professor deve rever sua postura em sala de aula, de forma a criar um ambiente que propicie a aprendizagem, e nesse momento, a partir da necessidade de adequar o trabalho escolar uma nova realidade.

Vale frisar que as aulas a partir dessas ferramentas, tiveram continuidade, a partir de um questionário realizado com as alunas da turma, sobre como estava na disciplina e como a mesma poderia melhorada, primando um melhor aprendizado. Abaixo, algumas respostas, em que as alunas foram nomeadas com letras do alfabeto, A, B, C, D e E, e colocam suas opiniões, conforme mostra a seguir:

\footnotetext{
"Este ano devido a pandemia está bem difícil num contexto geral em todos os conteúdos... mas felizmente matemática que tenho bastante dificuldade, tem sido a melhor de se aprender a senhora tem nos auxiliado perfeitamente... conteúdos bem elaborados... de fácil compreensão...não nos falta quando precisamos the questionar...os vídeos são excelentes pois parece que estamos tendo aulas presenciais, se continuar assim está muito bom.( Aluna A)"

"Pra min está tranquilo, apesar de ter as aulas das minhas filhas pra ajudar a fazer, eu estou conseguindo muito bem a partir do material e dos vídeos, $e$ ainda trabalho durante o dia, eu acho q quando a gente quer conseguir alguma coisa na vida tudo e difícil, então estou me esforçando pra isso e vamos conseguir. (Aluna B)".

"As aulas remotas de matemática estão de fácil acesso e a profe sempre a disposição para tirar dúvidas, auxilia no aprendizado com materiais e vídeos explicativos, nesses dias de dificuldade, incerteza e adaptação, as mensagens que recebo da profe de matemática de preocupação se estou entendendo e conseguindo fazer, me tranquiliza e aguça meu interesse pelo conteúdo que recebo, fazendo com que a distância fique um pouco menor. (Aluna C)"

"Acho que tá muito bom porque consigo acompanhar o seu conteúdo, e a senhora não sobrecarrega e ainda as explicações é como se tivesse na aula. Não estou conseguindo em outras matérias muito conteúdo, e aí tenho que tirar Xerox em cima de Xerox, e falta dinheiro, e matemática faço no caderno. (Aluna D) ".

"Profe consigo entender a disciplina de matemática, mesmo sendo uma matéria que tenho dificuldade, os vídeos e o passo a passo ajuda muito, porque sobra pouco tempo com os filhos em casa, dessa maneira é mais fácil, também sempre atender quando tenho dúvida. (Aluna E) ".
} 
Em um universo de quinze alunas, nem todas chegaram a responder o questionário. Das quinze, onze enviaram o retorno. A grande maioria prefere agradecer a atenção e o retorno que é dado, mas essas cinco falas acima, apontam que o uso do vídeo tem ajudado muito e que usar essa ferramenta parece muito com a aula presencial, facilitando o entendimento dos conceitos, mesmo perante a falta de equipamentos eletrônicos, vínculos frágeis com a vida escolar e família, dificuldades financeiras e outros, que aparecem também como fatores que tornam estas alunas mais suscetíveis.

Desse modo, os vídeos explicativos estão sendo uma das formas de minimizar os problemas dessa modalidade de ensino em relação aos conteúdos que estavam sendo ensinados e que precisavam ter continuidade através do ensino remoto, além de atividades enviadas pelo WhatsApp e na plataforma institucional. Moran (1993), defende o vídeo como importante na relação pedagógica, aproxima do cotidiano, além de introduzir novas questões no processo educacional.

Nesse sentido, a mediação é fundamental, conforme afirma Prado (2005, p. 10) “em relação ao uso do vídeo, se não houver a mediação do professor, em algum momento, pode se perder muito do potencial desta mídia, que pode trazer informações contextualizadas, por meio de uma linguagem própria, constituída pelo dinamismo de imagens e de sons".

A mesma autora também aponta que este recurso permite integração e permite que ao discente que esses conceitos sejam ressignificados:

\footnotetext{
na perspectiva da integração, em se tratando, por exemplo, do uso pedagógico do vídeo, a mediação do professor deve propiciar que as informações veiculadas por esta mídia sejam interpretadas, ressignificadas e, possivelmente, representadas em outras situações de aprendizagem (usando ou não os recursos da mídia), que possibilitem ao aluno transformar as informações em conhecimento (PRADO, 2005, p. 10).
}

Como a maioria dessas alunas está se readaptando à essa nova rotina de estudo, foi preciso que as organizações das aulas fossem repensadas e remodeladas, tendo como foco principal esses alunos, uma vez que eles têm muitas dificuldades de aprendizado. Vale dizer novamente, que em relação a essa turma, na maioria das vezes, são mães que além de cuidar da casa, trabalham fora, e, consequentemente, por falta de tempo acabam não se dedicando plenamente aos estudos, além disso, como mostra a fala da aluna, que muitas vezes não podem se dedicar ao estudo porque trabalham, têm filhos, família, entre 
outras preocupações. Dessa forma, é necessário sempre adaptar-se as formas de ensinar, utilizando metodologias que se tornem fáceis e efetivas, tendo o foco de manter a permanência e o êxito dessas alunas.

\section{Resultados e discussões}

O momento é de incertezas, não se sabe quais estratégias usar, quais são mais efetivas para garantir o mínimo de uma aprendizagem satisfatória, porém, é válido dizer, que essa foi uma atividade efetiva para essas alunas. Também é possível afirmar que nessa modalidade, a interação e o acolhimento são muito importantes, principalmente porque as alunas possuem angústias e dificuldades que abalam muitas vezes a vontade de concluir os estudos. Assim, o ensino remoto a partir dos meios virtuais não é tarefa fácil, nem para o docente e muito menos para os alunos, mas novas ferramentas precisam ser pensadas e utilizadas para garantir o êxito e permanência desses alunos.

Criar um grupo de WhatsApp somente para a disciplina, também ajudou a manter o vínculo e o diálogo com essas alunas, que vão muito além dos conceitos que devem ser ensinados pela disciplina, mas também palavras de solidariedade e motivação, que ajudam a cada uma continuar na instituição, apesar de todas as dificuldades e adversidades existentes em seus lares.

Importante citar, que muitas dessas alunas não possuem ambientes favoráveis para estudar em suas casas e tal fato, também precisa ser considerado. A instituição de ensino, na grande maioria das vezes, era o único espaço que estas tinham, além do incentivo e ajuda dos colegas e de todos os profissionais que a instituição possui.

O ensino remoto durante a pandemia fez com que o aluno se sentisse sozinho por não ter mais a aula presencial e verificou-se que o vídeo, pode ser um recurso didático de extrema importância para a aprendizagem, desde que seja usado com planejamento e critérios e objetivos específicos. Para Lima, Klein e Vieira (2010), os alunos têm maior motivação para a aprendizagem dos conhecimentos matemáticos, quando veem sentido e significado, pois facilitam o acesso e consequentemente o aprendizado das alunas no sentido de melhorar o entendimento dos conceitos matemáticos.

Para o ensino e aprendizagem dos conceitos matemáticos, é preciso considerar a construção dos conceitos e sua aplicabilidade em diferentes contextos, pois no PROEJA, 
a matemática é uma das disciplinas obrigatórias, em todos os cursos deve ser trabalhada sem perder de vista os objetivos a que se destina.

Os valores, ensino, teoria, prática, concepções e saberes não podem ser desprezados, bem como as características socioeconômicas, históricos e culturais e o meio em que o estudante é oriundo. E ao se pensar em alternativas para tornar mais eficaz o ensino da matemática, Paulo Freire (1996), diz que também para a eficácia, exige respeito aos saberes dos educandos, ética, aceitação do novo, reflexão, respeito à autonomia do educando, disponibilidade para o diálogo, mas ensinar exige, acima de tudo, alegria e esperança.

E nesse momento, as tecnologias ajudam ainda mais a alcançar os objetivos que se pretende atingir, adaptando o plano de trabalho ao momento que se vive aliado as situações de aprendizagem, adaptações necessárias nesse momento de distanciamento e que possam permitir uma melhor comunicação entre quem ensina e quem aprende e viceversa, procurando alternativas para desenvolver os conteúdos, despertando o interesse e interações.

Também é fundamental, que o ensino de matemática ocorra dentro do contexto da vida do aluno, a partir do seu cotidiano, considerando seus conhecimentos prévios, para que se obtenha uma aprendizagem mais significativa e contextualizada. As DCNs da Educação Básica (2013, p. 181), apontam o seguinte, em relação à contextualização, vejamos o que diz:

Nessa perspectiva, são também importantes metodologias de ensino
inovadoras, distintas das que se encontram nas salas de aula mais tradicionais
e que, ao contrário dessas, ofereçam ao estudante a oportunidade de uma
atuação ativa, interessada e comprometida no processo de aprender, que
incluam não só conhecimentos, mas, também, sua contextualização,
experimentação, vivências e convivência em tempos e espaços escolares e
extraescolares, mediante aulas e situações diversas.

Usar as tecnologias nas aulas de matemática como de qualquer outra disciplina requer certo domínio por parte do professor para que a orientação dada ao aluno seja correta e que o objetivo maior que é o aprendizado se realize.

Segundo a proposta curricular para Educação de Jovens e Adultos, a matemática deve aproveitar ao máximo o uso dos recursos tecnológicos:

O que se propõe hoje é que o ensino de matemática para jovens e adultos possa aproveitar ao máximo os recursos tecnológicos disponíveis, tanto por sua 
receptividade social como para melhorar a linguagem expressiva e comunicativa dos alunos jovens e adultos. (BRASIL, 2002, p. 29)

O uso de recursos tecnológicos, como vídeos educativos, pode torna-se um valioso instrumento, conforme é apresentado a seguir:

\footnotetext{
A utilização de vídeos educativos e softwares propicia uma apresentação dinâmica de conceitos, figuras, relações e gráficos - nos quais o ritmo e a cor são fatores estéticos importantes para captar o interesse do observador - e possibilita uma observação mais completa e detalhada, na medida em que permite parar a imagem, voltar, antecipar. (BRASIL, 2002, p. 29)
}

Porém, vale ressaltar que o professor tem papel fundamental neste processo, de nada adianta usar da tecnologia, sem planejamento e olhar atento aos discentes. A utilização do vídeo não substitui o professor, entretanto, nesse momento ajuda promover o ensino e aprendizagem, como ferramenta audiovisual que possibilita pesquisa e exploração, fazendo uso do recurso para ajudar para sanar as dúvidas.

\section{Considerações Finais}

O ensino na modalidade PROEJA mostra que os desafios são muitos e que o planejamento das aulas precisa ser diferente e que ensinar adultos exige cuidado. Para o ensino e aprendizagem dos conceitos matemáticos, é preciso considerar a construção dos conceitos e sua aplicabilidade em diferentes contextos. Esse momento que estamos vivendo, em virtude do Covid-19 com o ensino remoto, prevenindo a disseminação do Covid-19, as instituições escolares precisaram se reinventar, nesse sentido, foi preciso planejar atividades com materiais, que oferecem não só explicação do conceito e exercícios, mas também sugestões para apoiar os alunos a continuarem os estudos em casa e dar significado ao que estava sendo estudado, mesmo em tempos de dificuldades nunca vividos, nem pelas alunas e nem pelos professores.

Enfim, o contexto atual exigiu e está exigindo rearranjos, mais estudo e empatia, para permitir que as estratégias de ensino remoto sejam efetivas, usando de novas organizações que antes não eram tão usadas, como por exemplo, o uso de redes sociais como ferramenta mais próxima para chegar até os alunos, para também para manter os vínculos, indispensáveis no contexto atual.

As estratégias apresentadas nesse texto se constituem em metodologias que asseguram uma efetividade de ensino e aprendizagem no ensino da matemática. Porém, 
são apenas exemplos que estão sendo eficientes para essa turma de PROEJA e que precisaram ser reinventadas a partir da ausência dos espaços presenciais. Existem diversas outras possibilidades e ferramentas que o professor de matemática pode pensar e garantir as práticas pedagógicas que atendam a necessidade dos estudantes e consequentemente, possua eficácia e permanência nos estudos, mesmo sabendo que tudo que está sendo feito, não vai substituir a aula presencial.

\section{Referências}

BRASIL. Ministério da Educação. Conselho Nacional de Educação. Câmara de Educação Básica. Diretrizes Curriculares Nacionais da Educação Básica. Brasília: MEC, SEB, DICEI, 2013.

BRASIL. Ministério da Educação. Secretaria de Educação Média e Tecnológica. Parâmetros Curriculares Nacionais do Ensino Médio: Bases Legais. Brasília, DF: MEC, 2000.

BRASIL. Programa de Integração da Educação Profissional Técnica de Nível Médio ao Ensino Médio na Modalidade de Jovens e Adultos - PROEJA. Documento Base. Brasília: MEC, 2007.

FREIRE, Paulo. Pedagogia da autonomia: saberes necessários à prática educativa. São Paulo: Paz e Terra, 1996.

LIMA, M. G. P. B.; Klein, M. N. F.; Vieira, G. B. (2010). Motivação e Ensino: Fatores que Interferem na Aprendizagem do Aluno - Concepções de Professores do Proeja. In: Baracho, M. G; Moura, D. H (Org.). Programa Nacional de Integração da Educação Profissional com a Educação Básica na Modalidade de Educação Jovens e Adultos PROEJA- no IFRN: práticas pedagógicas e formação docente. Natal: IFRN Editora.

MORAN, José Manuel. Leituras dos meios de comunicação. São Paulo: Pancast, 1993.

OLIVEIRA, J. A.; PINHEIRO, N. A. M. Contextualizando a Matemática por meio de projetos de trabalho. In: Encontro Nacional de Pesquisa em Educação em Ciências - VII ENPEC. Anais. Florianópolis, SC, 2009. p. 1-12. Disponível em: < http://abrapecnet.org.br/enpec/xii-enpec/anais/lista_area_01_1.htm>. Acesso em 10 jul. 2000.

PRADO, M. E. B. B. Integração de tecnologias com as mídias digitais: integração de mídias e a reconstrução da prática pedagógica. Integração de tecnologias, linguagens e representações - Programa Salto para o Futuro. Maio, 2005. 
SILVA, L. T. P. P.; SANT’ANNA, S. M. L. Diversidade etária na EJA. In:

SANT'ANNA, S. M. L. Refletindo sobre Proeja: produções de São Vicente do Sul. Pelotas, RS: Editora Universitária - UFPEL, 2010. p. 67-82.

VALENTE, J. A. A espiral da espiral de aprendizagem: o processo de compreensão do papel das tecnologias de informação e comunicação na educação. 2005. Tese (LivreDocência) - Instituto de Artes, Universidade Estadual de Campinas, Campinas, 2005. Disponível em:

http://repositorio.unicamp.br/jspui/bitstream/REPOSIP/284458/1/Valente_JoseArmand o_LD.pdf. Acesso em 05 abr.2021.

Recebido em: 07 / 03 / 2021

Aprovado em: 18 / 04 / 2021 